\title{
Investigation of fungicidal activity of biocides by method of direct contact with test cultures
}

\author{
Valeriya Strokova ${ }^{1}$, Viktoriya Nelyubova $^{2 *}$ and Marina Rykunova $^{3}$ \\ ${ }^{1,2,3}$ BSTU named after V. G. Shukhov, Department of Materials Science and Technology, 308012 \\ Belgorod, Russia
}

\begin{abstract}
The article substantiates the possibility of using the method of direct contact with test cultures as an express method for assessing the quality of biocidal substances. This technique allows to test soluble biocidal preparations, while reducing the time of biocide selection, which eliminates the need for large-scale full-scale testing of structures under real operating conditions, providing cost savings.
\end{abstract}

\section{Introduction}

Biocorrosion is one of the most aggressive means of influencing building structures, significantly reducing their operational reliability $[1,2]$. The most large-scale method of eliminating the consequences of such impact is the use of bioactive substance [3-6], which are selected experimentally with a high material consumption and accompanying negative effects on the structure.

One of the most effective and lasting methods of protecting building materials and structures from damage by microorganisms is the use of chemical substances, namely biocides. It should be noted that liquid water-soluble biocides have a less pronounced toxicological effect on humans and the environment, which reduces pressure on the environment and energy intensity of production of materials with ensured biostability due to the ease of their introduction [7].

It is proposed to evaluate the fungicidal activity of biocides according to the method described in [8], the essence of which is the growth of cultures of mold fungi in solutions of biocidal additives. Using this method of assessing the fungicidal activity of biocides as express method will allow to optimize substance screening procedures, as it reduces the analysis time, reduces the consumption of substances and eliminates the need for largescale full-scale biocidal tests under real operating conditions. In addition, various preparations can be tested in a liquid medium, both on an alcoholic and a water basis.

\section{Materials and methods}

The most widely used in Russia commercial biocides were chosen as the tested bioactive substances: the disinfectant Dinovis manufactured by closed joint stock company

\footnotetext{
* Corresponding author: vvnelubova@gmail.com
} 
«Aldomed» (Tomsk) [9]; Disinfectant Megadez produced by closed joint stock company «Pilot and experimental plant VladMiVa» (Moscow) [10]. Dinovis is used as a means for disinfection of veterinary supervision objects and prevention of infectious animal diseases. It is an aqueous concentrate containing glyoxal, alkyl dimethylbenzylammonium chloride (catamine), 2-methylimidazole, functional components. Megadez is a highly effective disinfectant system based on alkyl dimethylbenzylammonium chloride (QAC / quaternary ammonium compounds) and glutaric aldehyde, the concentration of which ensures maximum substance efficacy and low toxicity of working solutions. For comparative analysis of the selected substances, entering into different groups according to the type of influence, the maximum and minimum concentrations declared by the manufacturers were chosen as test concentrations: Dinovis - 0.5 and $5 \%$; Megadez -0.5 and $5 \%$.

This choice is justified by the problem of resistance to disinfectants of pathogenic microorganisms. The use of biopreparations in deliberately large or not high concentrations contributes to the formation of resistance of microorganisms. In this regard, there is a need to monitor the stability of microflora to biocidal substances in order to improve the effectiveness of measures aimed at disinfection of premises of various types.

As test cultures, we used mold test cultures of the genera Aspergillus niger van Tieghem, Aspergillus terreus Thorn, Chaetomium globosum Kunze, Paecilomyces varioti Bainier, Penicillium cyclopium Westllng, Penicillium Purpureo, pure test cultures were obtained from the laboratory of fungal biochemistry at the Botanical Institute named after V.L. Komarov RAS.

To study the fungicidal activity of the active action preparations under study, microbiological test tubes were dispensed with 3-ml of prepared liquid non-agarinic nutrient Czapek medium that was sent for sterilization to an autoclave for 45 minutes at 120 ${ }^{\circ} \mathrm{C}$. After cooling, a suspension of test cultures was added to the test tubes in an amount of $0.5 \mathrm{ml}$, after that biocidal solutions with the studied concentrations were added taking into account aseptic rules in an amount of $0.5 \mathrm{ml}$, each component had a definite concentration in a finite volume.

Thus, there were three components in the test tubes, namely: a liquid nutrient medium, a suspension of test-culture spores, and a test preparation. The tubes were stored under optimal fungal growth conditions: at a temperature of $30{ }^{\circ} \mathrm{C}$ and a relative humidity of 95 $\%$.

As a control, test cultures grown in test tubes without the addition of growth inhibitors appeared. The growth of fungi was assessed visually on days 7 and 28 . Under absolute suppression of growth, tubes were taken in which the composition remained unchanged and transparent, and under complete absence of fungicide resistance, tubes that had a similarity to the control compounds, turbidity and new formations.

\section{Results and discussion}

According to the data obtained, Megadez and Dinovis absolutely suppress the growth of all molds not only in maximum, but also in minimum concentrations, therefore, they have absolute fungicidal properties (Fig. 1, 2); (for all the figures shown below in the text (Fig. 1-4): on the left - control, without the addition of biocide, in the center - the maximum recommended concentration of the preparation, on the right - the minimum recommended concentration). 


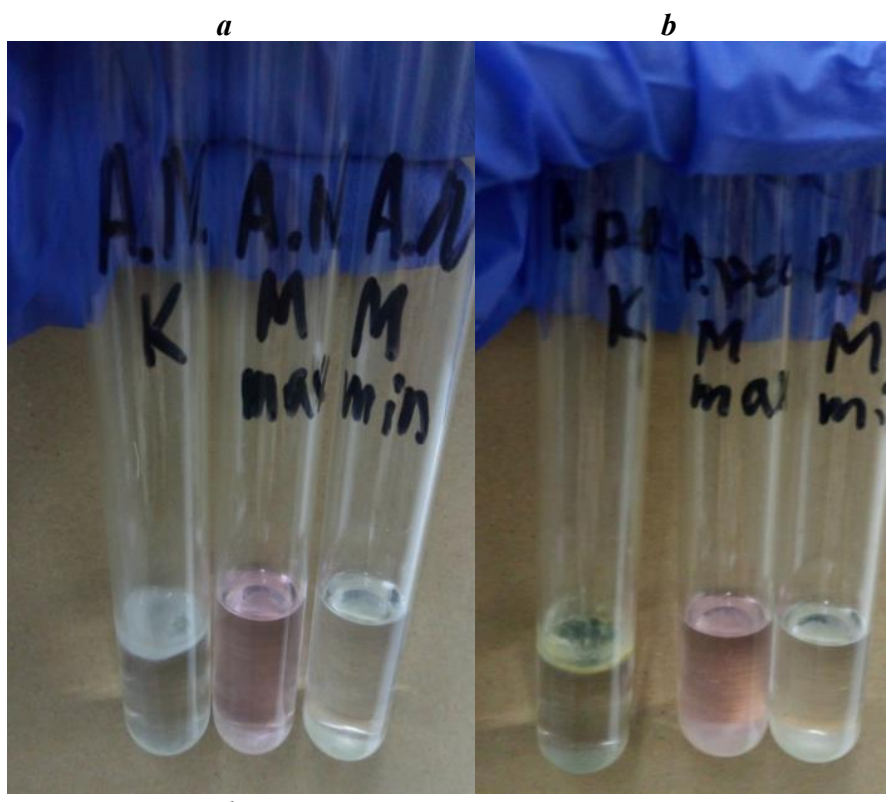

$d$

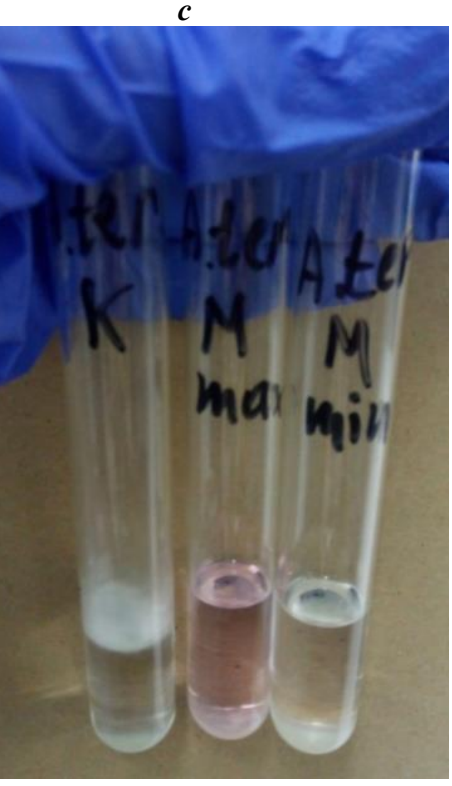

$f$

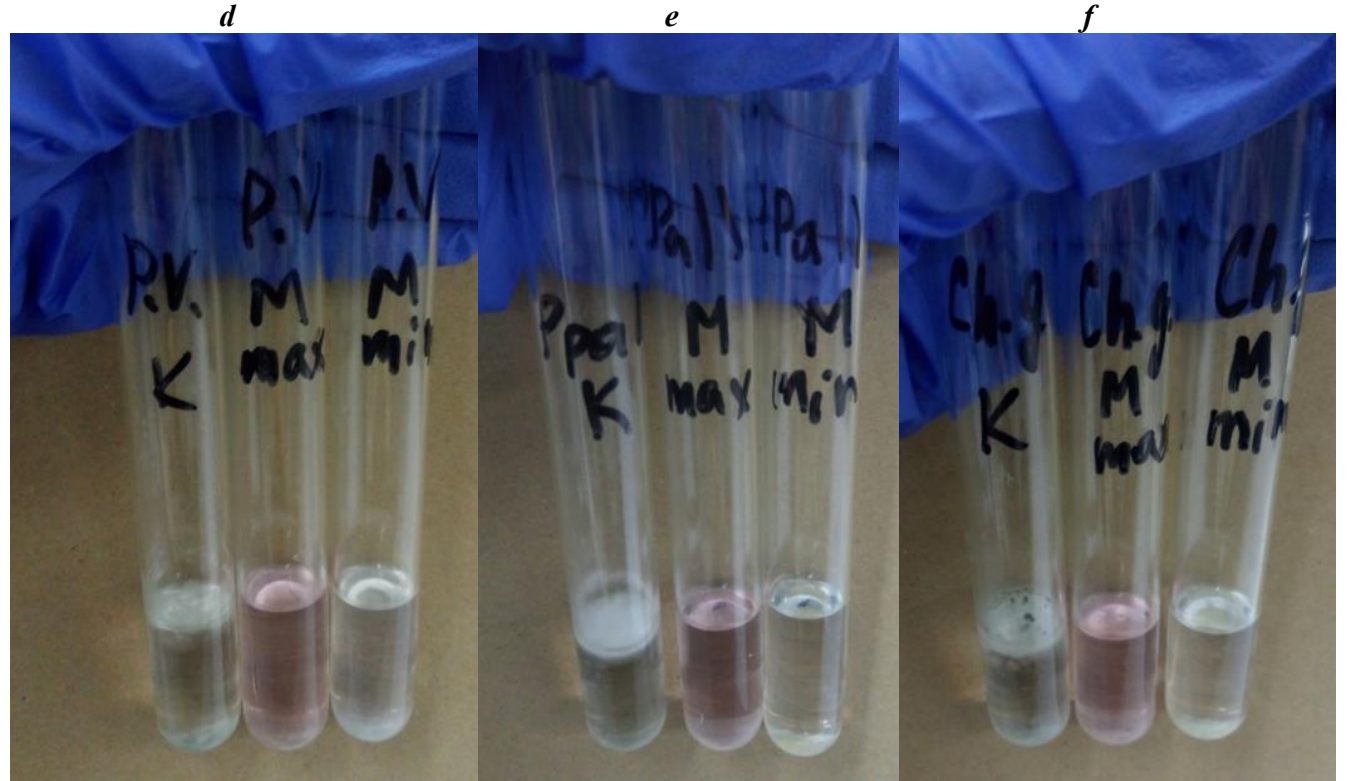

Fig. 1. Growth of fungi in the medium in the presence of Megadez after 7 days: $a$-Aspergillus niger; $b$-Penicillium cyclopium; $c$-Aspergillus terreus Thorn; $d$-Paecilomyces varioti; e-Penicillium purpureum; $f$-Chaetomium globosum.

To determine the prolonged fungicidal and fungistatic properties of the tested preparations, which showed qualitative results after 7 days, the test tubes continued to be stored under optimal fungal growth conditions and were re-examined after 28 days (Fig. 3, 4) (Table 1).

It should be noted that in Megadez and Dinovis absolute growth suppression for all fungi is observed even on the 28th day of aging, which confirms the high effectiveness of biocidal solutions, since according to the technical documentation for the indicated 
preparations their «working» solutions should be stored for no more than 14 days. An analysis of the results shows that the introduction of such additives in the composition of materials will provide a deterrent effect on the growth of the mycelium and most likely suppress the growth of fungi when in contact with the surface of the composite.

$\boldsymbol{a}$

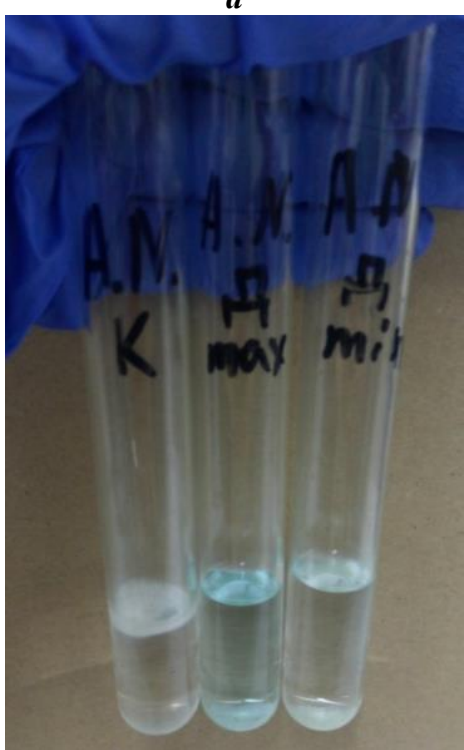

$d$ $b$

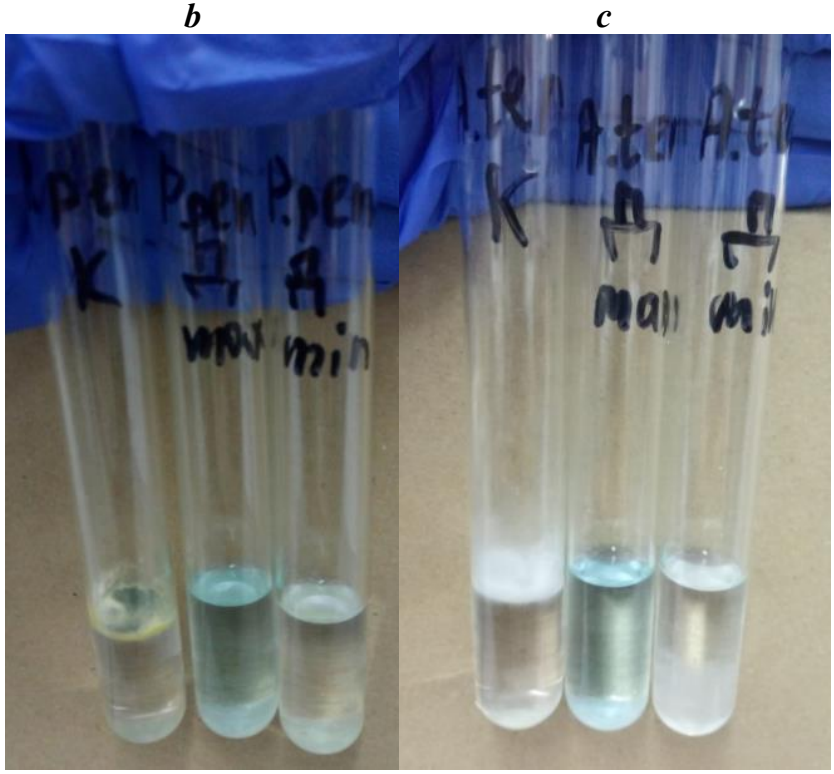

$\boldsymbol{e}$

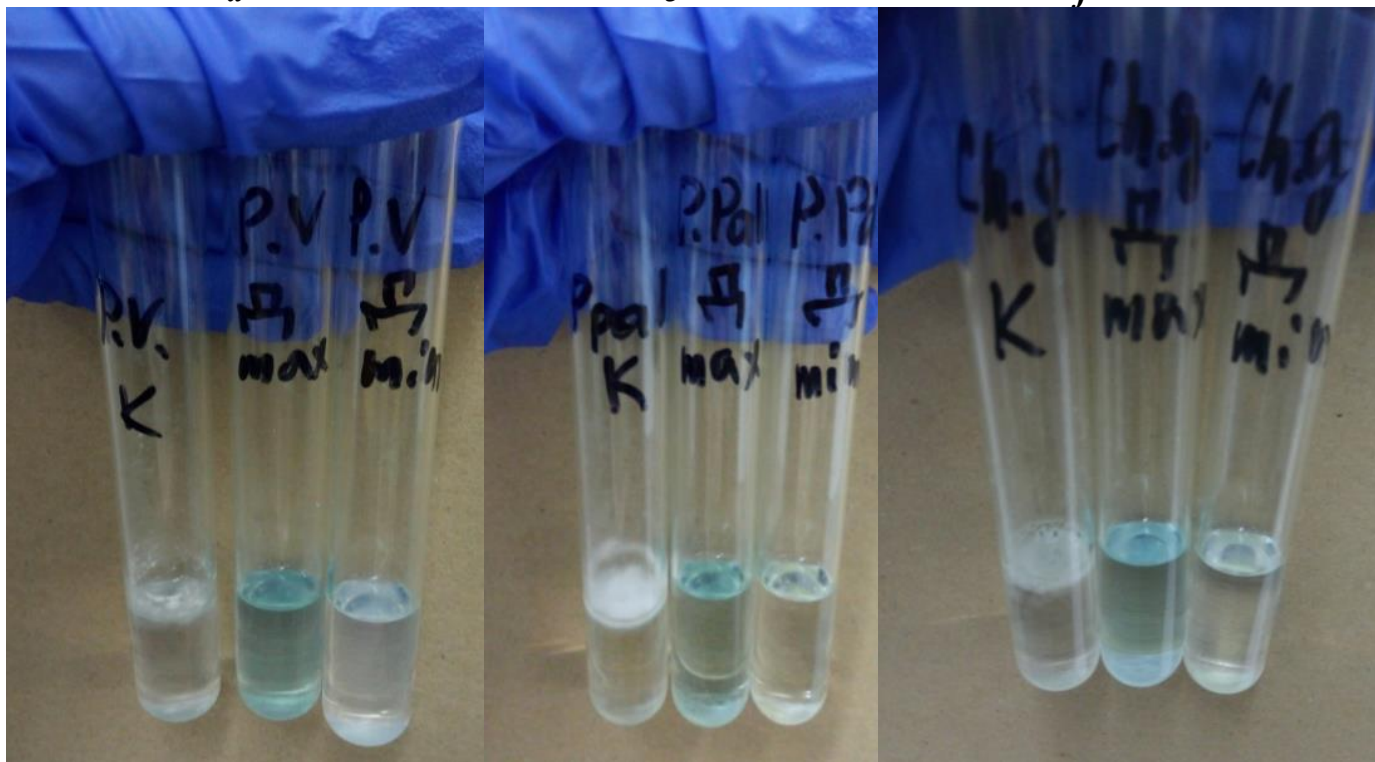

Fig. 2. Growth of fungi in the medium in the presence of Dinovis after 7 days: $a$-Aspergillus niger; $b$-Penicillium cyclopium; $c$-Aspergillus terreus Thorn; $d$-Paecilomyces varioti; $e$-Penicillium purpureum; $f$-Chaetomium globosum. 

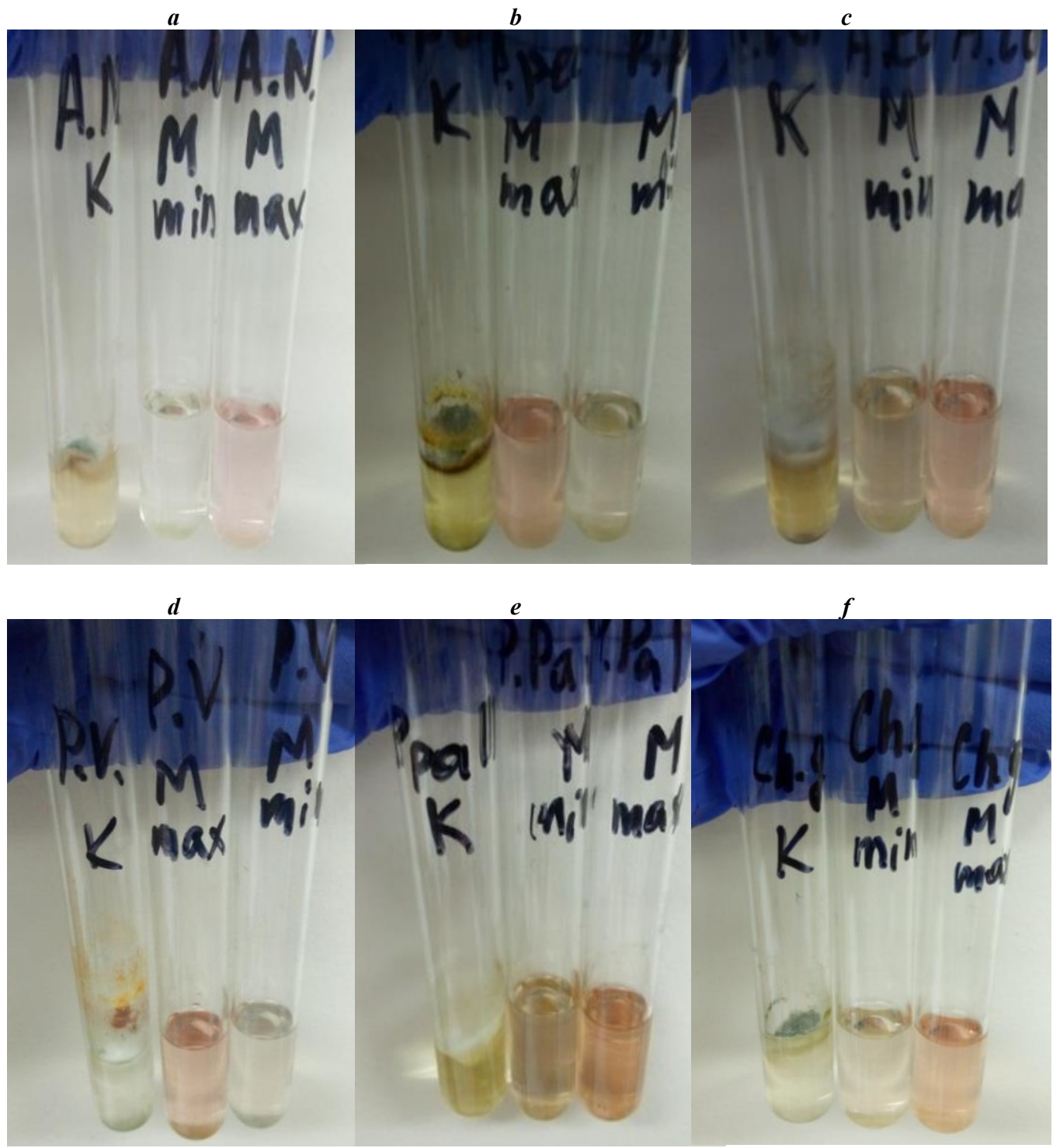

Fig. 3. Growth of fungi in the medium in the presence of Megadez after 28 days: $a$-Aspergillus niger; $b$ - Penicillium cyclopium; $c$-Aspergillus terreus Thorn; $d$-Paecilomyces varioti; $e-$ Penicillium purpureum; $f$-Chaetomium globosum. 
$a$

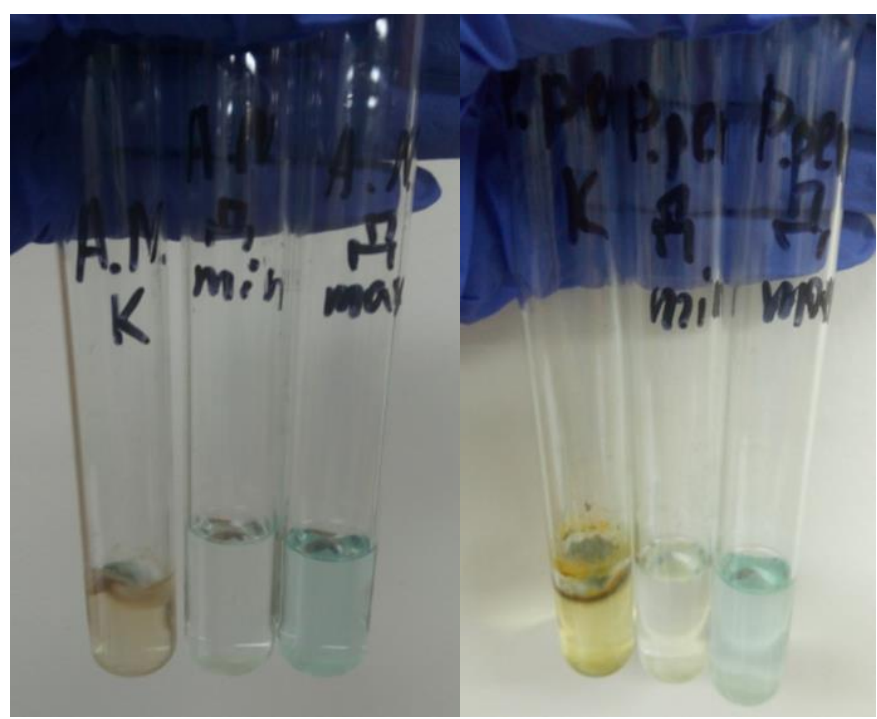

$\boldsymbol{d}$

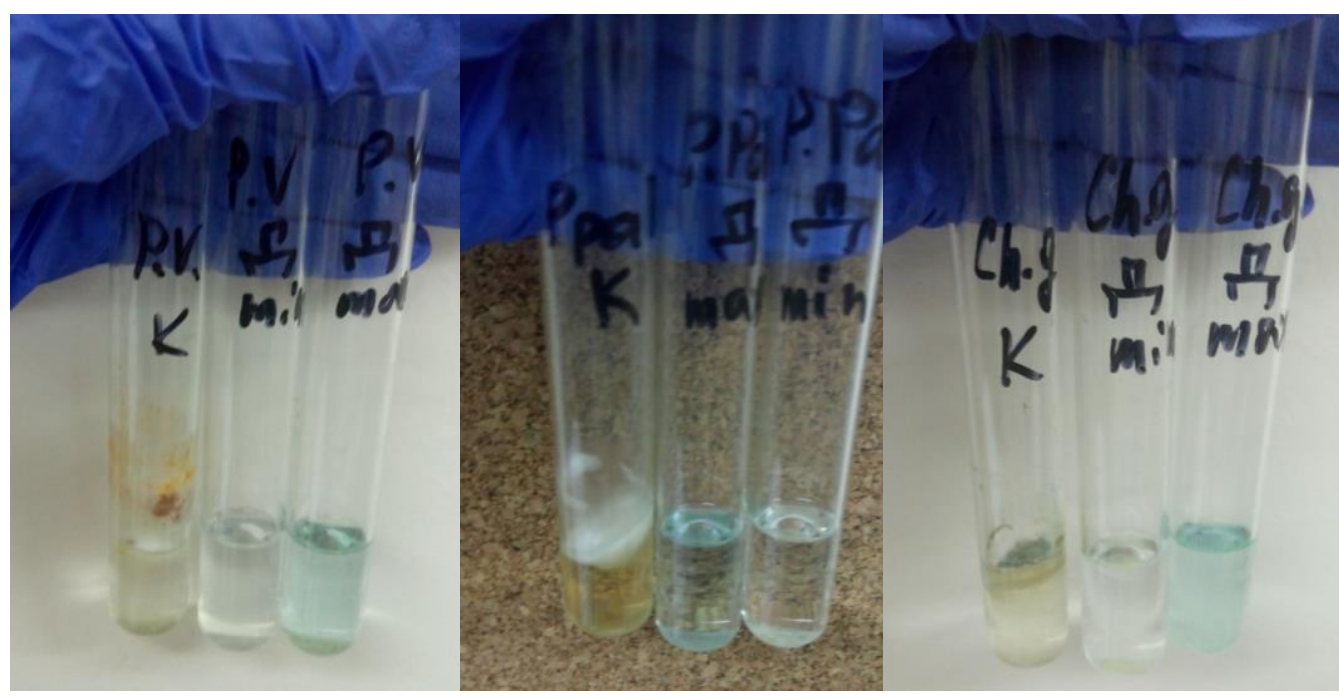

$c$

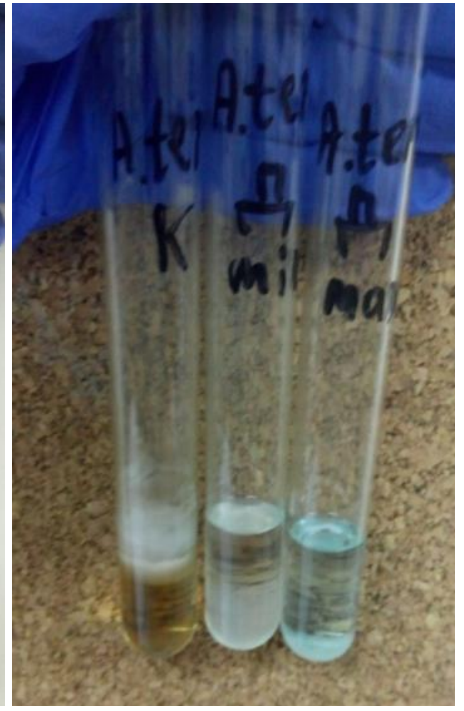

$f$

Fig. 4. Growth of fungi in the medium in the presence of Dinovis after 28 days: $a$-Aspergillus niger; $b$-Penicillium cyclopium; $c$-Aspergillus terreus Thorn; $d$-Paecilomyces varioti; $e-P e n i c i l l i u m$ purpureum; $f$-Chaetomium globosum.

On the whole, the results obtained make it possible to conclude the practicability of using Megadez and Dinovis preparations in order not only to prevent the growth of microscopic fungi - basic biodestructors, but also to destroy mycocenosis that are occupying the surface of materials. 
Table 1. Comparative characteristics of the effects of preparations on microscopic fungi at the age of 28 days.

\begin{tabular}{|c|c|c|c|c|c|c|c|}
\hline \multirow{2}{*}{$\begin{array}{c}\text { Preparati } \\
\text { on }\end{array}$} & $\begin{array}{c}\text { Concentrati } \\
\text { on, \% }\end{array}$ & $\begin{array}{c}\text { Aspergill } \\
\text { us niger }\end{array}$ & $\begin{array}{c}\text { Aspergill } \\
\text { us } \\
\text { terreus }\end{array}$ & $\begin{array}{c}\text { Chaetomi } \\
\text { um } \\
\text { globosum }\end{array}$ & $\begin{array}{c}\text { Paecilomy } \\
\text { ces variotii }\end{array}$ & $\begin{array}{c}\text { Penicilli } \\
\text { um } \\
\text { cyclopiu } \\
m\end{array}$ & $\begin{array}{c}\text { Penicilli } \\
\text { um } \\
\text { purpureu } \\
m\end{array}$ \\
\hline \multirow{2}{*}{ Dinovis } & 0,5 & + & + & + & + & + & + \\
\cline { 2 - 8 } & 5 & + & + & + & + & + & + \\
\hline \multirow{2}{*}{ Megadez } & 0,5 & + & + & + & + & + & + \\
\cline { 2 - 8 } & 5 & + & + & + & + & + & + \\
\hline
\end{tabular}

Note: «+» - fungicidal effect (absolute growth inhibition);

«土» - fungistatic effect (growth inhibition); «-»-no impact

Analyzing the data presented in Table 1, it can be concluded that all test cultures used are most sensitive to growth inhibitor drugs, which contain such active substances as: glyoxal and glutaric aldehyde. The obtained results not only confirm the data on the fungicidal properties of the preparations being studied, but are also probably more reliable, since they imply the direct contact of microorganisms with biologically active preparations.

\section{Conclusion}

Thus, this method is aimed at optimizing the selection of preparations used as an active component, providing a prolonged biostability of the material. The proposed technique allows testing of soluble biocidal preparations while reducing the time for biocide selection, taking into account the composition of the composite, as well as the mycocenosis formed on its surface, which eliminates the need for large-scale full-scale testing of structures under real operating conditions, providing cost savings. All this allows us to recommend it as an express method for assessing the quality of biocidal agents used as a fungicidal component for both sanation treatment and for use in composite materials. However, in the case of the latter, a complex of additional studies is needed to ensure the effective functioning of the bioactive component without changing the basic (regulated) construction and technical properties of the materials, which is the goal of further stages of work.

The research is made in the framework of State Task of the Russian Federation Ministry of Education and Science No. 7.872.2017/4.6. Development of principles for the design of ecologically positive composite materials with prolonged bioresistance. 2017-2019.

\section{References}

1. C. Thomas, A. Cimentada, J. A. Polanco, J. Setien, D. Mendez, J. Rico. Composites Part B-Engineering, vol. 45(1) (2013)

2. M. I. Vasilenko, E. N. Goncharova. Fundamental researches, vol. 8-1 (2013)

3. P. Maharjan, T. Clark, C. Kuenzel. Journal of applied poultry research, vol. 25 (2), (2016)

4. A. Carol Clausen, V. Yang. INT BI-ODETER BIODEGR, vol. 59 (2007)

5. S.J.F. Erich, V. Mendoza, W. Floor, S.P.M. Hermanns, W.J. Homan, and O.C.G. Adan, vol. 56 (3) (2011)

6. V.V. Strokova, V.V. Nelyubova, M. I. Vasilenko, E. N. Goncharova, M.D. Rykunova, E.K. Kalatozi. AIP Conference Proceedings, vol. 1899 (3) (2017) 
7. V.V. Strokova, M.D. Rykunova, V.V. Nelyubova, E.K. Kalatozi. International journal of advanced biotechnology and research, vol. 8 (4) (2017)

8. M.B. Dmitrieva. Butlerov messages, vol.33 (3) (2013)

9. Disinfectant "Dinovis", TU 9392-002-30407785-2012 with changes. 1.

10. Disinfectant "Megadez", TU 9392-103-45814830-2006. 